\title{
EFEKTIVITAS MODEL PEMBELAJARAN KOOPERATIF TIPE QUIZ TEAM TERHADAP HASIL BELAJAR BIOLOGI SISWA PADA MATERI SISTEM PERNAPASAN MANUSIA DI KELAS XI IPA SMA DHARMA PANCASILA MEDAN
}

\author{
Novalia Rosanna Evalin Hasugian, Aryeni \\ Program Studi Pendidikan Biologi, FMIPA, Universitas Negeri Medan, Medan \\ Jl. Willem Iskandar Psr. V Medan Estate, Medan, Indonesia, 20221 \\ Email : novalia.hasugian@ymail.com
}

\begin{abstract}
ABSTRAK
Penelitian ini bertujuan untuk mengetahui kefektifan pembelajaran biologi siswa dengan menggunakan model pembelajaran kooperatif tipe Quiz Team pada materi Sistem Pernapasan Manusia di kelas XI IPA SMA Dharma Pancasila Medan Tahun Pembelajaran 2016/2017. Populasi penelitian ini adalah seluruh siswa kelas XI IPA SMA Dharma Pancasila Medan yang terdiri dari 3 kelas dan jumlah seluruhnya 93 orang siswa. Pengambilan sampel dalam penelitian ini ditentukan secara acak (random sampling) yaitu kelas XI IPA 2 yang terdiri dari 31 orang. Penelitian ini merupakan penelitian pre-experiment. Instrumen yang digunakan untuk mengumpulkan data adalah tes objektif dalam bentuk pilihan ganda yang telah diuji cobakan validitas, reliabilitas, tingkat kesukaran dan daya pembeda. Instrumen yang digunakan sebanyak 25 soal. Dari hasil analisis data diperoleh hasil observasi aktivitas sudah terlaksana dengan baik dan siswa aktif, dari hasil belajar nilai rata-rata tes awal (pretest) adalah 56.00 dan nilai rata-rata tes akhir (post test) yaitu 80.26. Berdasarkan hasil data, efektivitas dapat digambarkan dengan ketuntasan belajar secara individual sebanyak 28 siswa tuntas (90.32\%) dan 3 orang siswa tidak tuntas (9.68\%). Efektivitas treatment juga sudah terpenuhi dimana $t_{\text {hitung }}$ lebih besar dari $t_{\text {tabel }}$ yaitu $14.42>1.6973$ dan persen peningkatan hasil belajar ( $N$-Gain) berada pada kategori sedang yaitu 0.56 . Sehingga dapat disimpulkan bahwa penggunaan model pembelajaran Quiz Team pada materi sistem pernapasan manusia di kelas XI IPA SMA Dharma Pancasila Medan Tahun Pembelajaran 2016/2017 adalah efektif.
\end{abstract}

Kata Kunci: Quiz Team, Efektivitas, Hasil Belajar

\begin{abstract}
This study aims to determine the effectiveness of student biology learning using cooperative learning model type Quiz Team on Human Respiratory System material in class XI IPA SMA Dharma Pancasila Medan Year Learning 2016/2017. The population of this study is all students of class XI IPA SMA Dharma Pancasila Medan consisting of 3 classes and the total of 93 students. Sampling in this study was determined randomly (random sampling) that class $\mathrm{XI} \mathrm{IPA}_{2}$ consisting of 31 people. This research is a pre-experiment research. Instruments used to collect data are objective tests in multiple choice that have been tested to try validity, reliability, difficulty and distinguishing power. Instruments used as many as 25 questions. From the result of data analysis, the result of activity observation have been done well and active student, from learning result of pretest average value is 56,00 and mean value of final test (post test) that is 80,26 . Based on result Data, effectiveness can be described with complete learning individually as many as 28 students complete (90,32\%) and 3 student unfinished (9,68\%). The effectiveness of treatment has also been met where t count is bigger than ttable that is 14,42 $>1,6973$ and percent increase of learning result ( $\mathrm{N}$-Gain) is in medium category that is 0,56 . So it can be concluded that the use of learning model Quiz Team on human respiratory system material in class XI IPA SMA Dharma Pancasila Medan Year Learning 2016/2017 is effective.
\end{abstract}

Keywords: Quiz Team, Effectiveness, Learning Outcomes 


\section{PENDAHULUAN}

Sebagai tenaga pengajar di sekolah guru memegang peranan penting dalam keberhasilan kegiatan pembelajaran di kelas. Dimana kegiatan pembelajaran di kelas memerlukan adanya keaktifan belajar siswa, partisipasi siswa dalam pembelajaran dan komunikasi interaktif siswa dengan guru. Khusus untuk mata pelajaran biologi sebagai bagian dari IPA menyediakan berbagai pengalaman belajar untuk memahami konsep dan proses sains. Dalam proses belajar mengajar di kelas terdapat keterkaitan yang erat antara guru, siswa, kurikulum, sarana dan prasarana. Guru mempunyai tugas untuk dapat mengupayakan model pembelajaran yang tepat sesuai dengan tingkat perkembangan mental siswa. Untuk itu diperlukan model pembelajaran yang dapat membantu siswa untuk mencapai kompetensi dasar dan indikator pembelajaran (Ziqri dan Supriyanto, 2014).

Berdasarkan observasi yang telah dilakukan bahwa hasil belajar biologi siswa di kelas XI IPA SMA Dharma Pancasila Medan masih rendah. Dimana KKM mata pelajaran biologi di sekolah yaitu 75 sementara siswa yang mendapat nilai dibawah KKM ada sekitar $60 \%$ dari jumlah siswa. Proses pembelajaran juga masih terkesan teacher-centered learning meskipun guru sudah menggunakan metode diskusi dan tanya jawab. Hal tersebut dapat dilihat bahwa siswa kurang aktif dan kegiatan diskusi kurang berjalan baik atau belum terdapat kerja sama antar siswa. Kemudian sebagian siswa masih kurang peduli terhadap proses pembelajaran. Juga kurangnya interaksi sosial antara siswa baik dalam bekerja sama maupun ketika berkomunikasi.

Quiz Team merupakan salah satu tipe pembelajaran kooperatif yang mampu meningkatkan hasil belajar siswa. Berdasarkan penelitian yang telah dilakukan oleh Ningrum (2015) disimpulkan bahwa hasil pengumpulan data yang dikumpulkan dari 24 siswa yang diberikan perlakuan (treatment) dengan model Quiz Team, hasil belajar Kewirausahaan siswa yang masuk dalam kategori tuntas sebanyak 58,33\% yaitu 14 siswa dan yang belum tuntas $41,67 \%$ yaitu
10 siswa. Hasil ini menunjukkan bahwa hasil belajar siswa meningkat dengan menggunakan model pembalajaran kooperatif tipe Quiz Team. Dan penelitian yang dilakukan oleh Rejeki dan Rohadi (2014) tentang penerapan model cooperative learning tipe Quiz Team disimpulkan bahwa hasil belajar dan partisipasi siswa dalam mengikuti proses pembelajaran mengalami peningkatan. Serta penelitian yang dilakukan oleh Ayunda, dkk (2013) disimpulkan bahwa penerapan pembelajaran aktif teknik Quiz Team dapat meningkatkan hasil belajar biologi siswa.

Materi yang digunakan dalam penelitian ini adalah sistem pernapasan manusia. Materi sistem pernapasan manusia merupakan salah satu materi dalam pembelajaran biologi yang cukup kompleks. Materi ini memuat teori dan konsep-konsep dasar mengenai struktur, fungsi dan proses pada sistem pernapasan manusia. Ada beberapa indikator dari materi yang kompleks dan membutuhkan pemahaman dan interaksi yang besar antar siswa agar bisa memahami materi ini dengan baik misalnya indikator memahami mekanisme pertukaran gas, dan menjelaskan mekanisme pernapasan dada dan pernapasan perut (Saenab dan Puspita, 2012).

Adapun yang menjadi tujuan dalam penelitian ini adalah sebagai berikut. Untuk memperoleh informasi tentang aktivitas siswa dalam pembelajaran, hasil belajar, ketuntasan belajar dan efektifitas treatment model pembelajaran kooperatif tipe Quiz Team di kelas XI IPA SMA Dharma Pancasila Medan.

\section{METODE PENELITIAN}

Pengumpulan data maupun informasi yang dibutuhkan dalam penelitian ini dilaksanakan di SMA Dharma Pancasila Medan. Penelitian ini dilaksanakan dari bulan Maret sampai dengan Mei 2017.

Populasi pada penelitian ini adalah seluruh kelas XI IPA SMA Dharma Pancasila Medan Tahun Pembelajaran 2016/2017 berjumlah 93 siswa, terdiri dari 3 kelas yakni, XI IPA, XI IPA Ian XI IPA $_{3}$. 
Penentuan sampel dilakukan secara random (acak). Dan terpilih kelas XI IPA 2 berjumlah 31 siswa.

Jenis penelitian ini adalah pre-eksperiment. Instrumen penelitian ini yaitu observasi. aktivitas siswa dan tes objektif berupa soal pilihan ganda sebanyak 25 soal. Variabel bebas (X) dalam penelitian ini adalah model pembelajaran kooperatif tipe Quiz Team dan variabel terikat (Y) yaitu hasil belajar biologi siswa kelas XI IPA SMA Dharma Pancasila Medan Tahun Pembelajaran 2016/2017.

Teknik analisis data yang dilakukan yaitu menilai aktivitras siswa menggunkan lembar observasi. Menghating Untuk mengetahui perbedaan hasil pretest dan post test digunakan uji Efektivitas Treatment dan diperkuat dengan N-Gain untuk mengetahui persen peningkatan hasil belajar.

\section{HASIL PENELITIAN}

Untuk melihat aktivitas siswa dalam penelitian ini diperoleh berdasarkan perhitungan nilai dari lembar observasi yang dilakukan observer selama proses pembelajaran biologi pada materi Sistem Pernapasan Manusia dengan menggunakan model pembelajaran kooperatif tipe Quiz Team. Berdasarkan pengamatan yang telah dilakukan, secara klasikal kategori aktivitas siswa dari pertemuan I sampai Pertemuan IV rata-ratanya yaitu $65,88 \%$ yang termasuk kedalam kategori aktif.

Nilai hasil belajar diperoleh dari tes yang dilakuakan diawal dan diakhir proses pembelajaran dengan menggunakan model pembelajaran kooperatif tipe Quiz Team. Nilai hasil belajar siswa pada materi sistem pernapasan manusia pada tes awal (pretest) dan test akhir (post test). Nilai ratarata siswa yang diberikan tes awal (pretest) yaitu 56,00 . Sedangkan nilai rata-rata siswa saat diberi tes akhir (post test) yaitu 80,26. Adapun ringkasan presentase hasil belajar siswa tersaji pada Tabel 1, dan Tabel 2. bawah ini.

Tabel 1. Persentase Hasil Belajar Siswa Saat Tes Awal (Pretest)

\begin{tabular}{ccccc}
\hline No & Nilai Tes & Kategori & Banyak Siswa & Persentase Jumlah Siswa \\
\hline 1 & $86-100$ & Sangat Baik & 0 & $0 \%$ \\
2 & $71-85$ & Baik & 3 & $9,68 \%$ \\
3 & $56-70$ & Cukup & 12 & $38,70 \%$ \\
4 & $41-55$ & Kurang & 15 & $48,39 \%$ \\
5 & $0-40$ & Sangat Kurang & 1 & $3,23 \%$ \\
\hline
\end{tabular}

Tabel 2. Persentase Hasil Belajar Siswa Saat Tes Akhir (Post test)

\begin{tabular}{ccccc}
\hline No & Nilai Tes & Kategori & Banyak Siswa & Persentase Jumlah Siswa \\
\hline 1 & $86-100$ & Sangat Baik & 9 & $29,03 \%$ \\
2 & $71-85$ & Baik & 19 & $61,29 \%$ \\
3 & $56-70$ & Cukup & 2 & $6,45 \%$ \\
4 & $41-55$ & Kurang & 0 & $0,00 \%$ \\
5 & $0-40$ & Sangat Kurang & 1 & $3,23 \%$ \\
\hline
\end{tabular}

Dari kedua tabel dapat dilihat adanya peningkatan hasil belajar pada pembelajaran yang menggunakan model pembelajaran kooperatif tipe Quiz Team pada materi sistem pernapasan manusia.
Hal ini karena rata-rata nilai pretest masih tergolong kurang sedangkan rata-rata nilai post test sudah tergolong baik. 
Untuk menentukan efektivitas dalam pembelajaran sistem pernapasan manusia di kelas XI $\mathrm{IPA}_{2}$ SMA Dharma Pancasila Medan menggunakan model Quiz Team dalam penelitian ini salah satunya didasarkan pada kriteria ketuntasan belajar siswa.
Tingkat ketuntasan belajar siswa diketahui dari hasil post test. Persentase tingkat ketuntasan belajar siswa dalam pembelajaran sistem pernapasan manusia menggunakan model Quiz Team disajikan dalam Tabel 3. Berikut.

Tabel 3. Persentase Tingkat Ketuntasan Siswa

\begin{tabular}{ccccc}
\hline No & Nilai Tes & Tingkat Ketuntasan & Jumlah Siswa & Persentase Jumlah Siswa \\
\hline 1 & $<75$ & Tidak Tuntas & 3 & $9,68 \%$ \\
2 & $\geq 75$ & Tuntas & 28 & $90,32 \%$ \\
\hline
\end{tabular}

Berdasarkan Tabel 3 di atas, terdapat 3 orang siswa atau 9,68\% yang belum tuntas belajar. Banyaknya siswa yang berada pada tingkat hasil belajar tuntas yaitu sebanyak 28 orang siswa atau $90,32 \%$ (memenuhi kriteria $\geq 85 \%$ ). Dalam hal ini berdasarkan kriteria ketuntasan belajar secara klasikal dapat dikatakan kelas ini sudah tuntas belajar dalam menyelesaikan soal materi sistem pernapasan manusia.

Efektivitas treatment merupakan salah satu cara perhitungan yang dapat digunakan untuk mengukur efektivitas suatu model pembelajaran. Berdasarkan data efektivitas treatment dalam pembelajaran sistem pernapasan manusia diperoleh $t_{\text {hitung }}=14,42$ dan $t_{\text {tabel }}=1,6973$. Hal tersebut membuktikan bahwa model pembelajaran kooperatif tipe Quiz Team efektif dalam pembelajaran sistem pernapasan manusia karena $t_{\text {hitung }}>t_{\text {tabel }}$ yaitu 14,42 $>$ 1,6973. Jadi kesimpulannya yaitu $\mathrm{H} 1$ diterima dan $\mathrm{HO}$ ditolak dimana $\mathrm{H} 1$ adalah ada perbedaan secara signifikan antara hasil pretest dengan post test pada penggunaan model pembelajaran kooperatif tipe Quiz Team terhadap hasil belajar biologi siswa pada materi sistem pernapasan manusia di kelas XI IPA SMA Dharma Pancasila Medan. Hasil analisis statistik diperkuat melalui analisis $N$-Gain untuk mengetahui berapa persen peningkatan hasil belajar siswa.yang dapat dilihat dari Tabel 4. berikut ini. Berdasarkan Tabel 4hasil analisis $N$-Gain diperoleh bahwa hasil belajar siswa setelah diterapkan model pembelajaran kooperatif tipe Quiz Team mengalami peningkatan pada kategori sedang dengan rata-rata 0,56 \%.

Tabel 4. Klasifikasi N-Gain pada Kelas XI IPA2

\begin{tabular}{cccc}
\hline Koefisien N-Gain & Banyaknya Siswa & Persentase (\%) & Klasifikasi \\
\hline $\mathrm{g} \geq 0,7$ & 5 & 16,13 & Tinggi \\
$0,3 \leq \mathrm{g}<0,7$ & 25 & 80,65 & Sedang \\
$\mathrm{g}<0,3$ & 1 & 3,23 & Rendah \\
\hline Rata-rata N-gain & & $\mathbf{0 . 5 6}$ & Sedang \\
\hline
\end{tabular}

\section{PEMBAHASAN}

Hasil pengamatan aktivitas siswa dalam pembelajaran dengan menggunakan model Quiz Team diperoleh dari lembar observasi. Penilaian aktivitas siswa yang dilakukan oleh observer, observer yang digunakan berjumlah 4 orang mahasiswa dimana masing-masing observer mengamati satu aktivitas dari setiap siswa. Penilaian aktivitas siswa yang dilakukan observer saat proses belajar mengajar yaitu akivitas visual, aktivitas lisan, aktivitas audio dan aktivitas menulis. Dengan adanya aktivitas siswa membuat proses mengajar dapat terlaksana, tanpa adanya aktivitas maka proses 
pembelajaran tidak mungkin terjadi. Dengan demikian semakin aktif siswa dalam proses pembelajaran maka semakin efektif model pembelajaran kooperatif tipe Quiz Team dan proses pembelajaran dikatakan baik. Berdasarkan hasil penelitian mengenai lembar observasi aktivitas belajar siswa secara klasikal kategori aktivitas siswa dari pertemuan I sampai pertemuan IV rata-ratanya yaitu 65,88 yang termasuk kedalam kategori aktif. Berdasarkan hasil penelitian mengenai lembar observasi aktivitas belajar siswa secara klasikal kategori aktivitas siswa dari pertemuan I sampai pertemuan IV rata-ratanya yaitu 65,88 yang termasuk kedalam kategori aktif. Hal ini juga didukung oleh penelitian dilakukan oleh Rejeki dan Rohadi (2014) tentang penerapan model cooperative learning tipe Quiz Team disimpulkan bahwa hasil belajar dan partisipasi siswa dalam mengikuti proses pembelajaran mengalami peningkatan.

Berdasarkan hasil analisis terhadap skor yang diperoleh siswa terlihat bahwa pada tes awal (pretest) dari 31 siswa 3 siswa termasuk ke dalam kategori baik, 12 siswa termasuk ke dalam kategori cukup, 15 siswa termasuk ke dalam kategori kurang dan 1 siswa termasuk ke dalam kategori sangat kurang. Pada tes akhir (post test) dari 31 siswa 9 siswa termasuk ke dalam kategori sangat baik, 19 siswa termasuk ke dalam kategori baik, 2 siswa termasuk ke dalam kategori cukup dan 1 siswa termasuk ke dalam kategori sangat kurang. Hasil belajar siswa yang diperoleh dari nilai pretest dan post test terlihat bahwa nilai post test lebih tinggi daripada nilai pretest, sehingga dapat dikatakan bahwa tujuan mengajar dapat tercapai. Hasil belajar ini juga menunjukkan bahwa model pembelajaran kooperatif tipe Quiz Team efektif dalam penguasaan siswa terhadap materi yang diajarkan, karena terbukti adanya perubahan peningkatan nilai setelah dilakukan pembelajaran dengan menggunakan model pembelajaran kooperatif tipe Quiz Team tersebut. Hal ini juga sesuai dengan penelitian yang dilakukan Ayunda, dkk (2013) disimpulkan bahwa penerapan pembelajaran aktif teknik Quiz Team dapat meningkatkan hasil belajar biologi siswa.

Dalam menganalisis ketuntasan belajar secara individual dan ketuntasan belajar menurut Depdikbud dalam Trianto (2009) mengatakan bahwa setiap siswa dikatakan tuntas belajarnya (ketuntasan individual) jika proporsi jawaban benar siswa $\geq 65 \%$ dan suatu kelas dikatakan tuntas belajarnya (ketuntasan klasikal) jika kelas tersebut terdapat $\geq$ 85\% siswa yang telah tuntas belajarnya. Tetapi berdasarkan KTSP penentuan ketuntasan belajar ditentukan sendiri oleh masing-masing sekolah yang dikenal dengan istilah kriteria ketuntasan minimal. Untuk keperluan analisis tersebut, disusun suatu kriteria ketuntasan minimal (KKM) siswa dalam belajar yang diterapkan di SMA Dharma Pancasila Medan, yaitu siswa yang mendapatkan nilai 75 atau lebih berada dalam kategori tuntas. Sedangkan siswa yang mendapatkan nilai dibawah 75 berada dalam kategori tidak tuntas. Jadi pada penelitian ini ketuntasan belajar secara klasikal telah terpenuhi karena lebih dari $85 \%$ siswa dinyatakan telah tuntas belajar berdasarkan pencapaian nilai tes $\geq 75$. Hasil ini menunjukkan bahwa penggunaan model pembelajaran kooperatif tipe Quiz Team efektif terhadap hasil belajar siswa dan dapat digunakan sebagai salah satu model alternatif yang dapat digunakan agar hasil belajar menjadi tuntas baik secara individual maupun klasikal. Meskipun secara umum pembelajaran dengan menggunakan model pembelajaran kooperatif tipe Quiz Team ini telah tuntas, namun masih ada 3 orang siswa yang belum tuntas belajar secara individual. Salah satu penyebabnya aktivitas siswa tersebut pada proses pembelajaran masih kurang aktif. Sedangkan siswa yang telah tuntas dalam belajar dikarenakan siswa sudah aktif pada proses pembelajaran, sehingga pada saat posttest siswa dapat mengingat materi yang telah dipelajari. Hal ini diperkuat oleh pendapat Slameto (2010) yang menyatakan bahwa bila siswa menjadi parstisipasi yang aktif, maka dia memiliki pengetahuan yang baik. 
Berdasarkan data efektivitas treatment dalam pembelajaran sistem pernapasan manusia $t_{\text {hitung }}$ yang diperoleh lebih besar dari $t_{\text {tabel. }}$ Hal tersebut membuktikan bahwa model pembelajaran kooperatif tipe Quiz Team efektif dalam pembelajaran sistem pernapasan manusia. Jadi kesimpulannya yaitu $\mathrm{H} 1$ diterima dan $\mathrm{HO}$ ditolak, dimana $\mathrm{H} 1$ yaitu ada perbedaan secara signifikan antara hasil pretest dengan posttest pada penggunaan model pembelajaran kooperatif tipe Quiz Team terhadap hasil belajar biologi siswa pada materi sistem pernapasan manusia di kelas XI IPA SMA Dharma Pancasila Medan. Hasil analisis statistik diperkuat melalui analisis $\mathrm{N}$-Gain untuk mengetahui berapa persen peningkatan hasil belajar siswa. Hasil analisis $\mathrm{N}$-Gain diperoleh bahwa hasil belajar siswa setelah diterapkan model pembelajaran kooperatif tipe Quiz Team mengalami peningkatan pada kategori sedang dengan rata-rata 0,56 .

\section{KESIMPULAN}

Hasil belajar siswa menggunakan model pembelajaran kooperatif tipe Quiz Team pada materi sistem pernapasan manusia di kelas XI IPA SMA Dharma Pancasila Medan menunjukkan peningkatan dimana rata-rata nilai tes awal (pretest) yaitu 56,00 sedangkan rata-rata nilai tes akhir (post test) yaitu 80,26 . Pembelajaran biologi menggunakan model pembelajaran kooperatif tipe Quiz Team pada materi sistem pernapasan manusia di kelas XI IPA SMA Dharma Pancasila Medan dinyatakan efektif karena hasil observasi aktivitas belajar siswa terlaksana dengan baik, nilai hasil belajar terpenuhi, ketuntasan belajar siswa secara perseorangan dan secara klasikal termasuk kategori tuntas dan efektivitas treatment terpenuhi.

\section{DAFTAR PUSTAKA}

Ayunda, F., P., Mulyati, dan Nerita, S., (2013), Pengaruh Penerapan Pembelajaran Aktif Teknik Quiz Team Disertai Bahan Ajar Terhadap Hasil Belajar Biologi Siswa Kelas VIII
MTsN Lubuk Sikaping Tahun Pelajaran 2012/2013, Jurnal Mahasiswa Pendidikan Biologi, 2(2): $1-6$.

Ningrum, (2015), Pengaruh Penerapan Model Active Learning Tipe Team Quiz Terhadap Hasil Belajar Kewirausahaan Siswa Kelas $X$ Semester Genap SMK Kartikatama Metro Tahun Pelajaran 2014/2015, Jurnal Pendidikan Ekonomi UM Metro, 3(1): 93 - 103.

Rejeki, V., S., dan Rohadi, N., (2014), Penerapan Model Cooperative Learning Tipe Quiz Team untuk Meningkatkan Partisipasi dan Hasil Belajar siswa Kelas XI IPA 1 di MAN 1 Kota Bengkulu, Jurnal Exacta, 12(2): 52 - 57.

Saenab, S., dan Puspita I., (2012), Peningkatan Aktivitas dan Hasil Belajar Biologi Melalui Penerapan Model Pembelajaran Kooperatif Tipe Think Pair Share (TPS) pada Siswa Kelas XI IPA 2 SMA Negeri 1 Mangkutana, Jurnal Bionature, 13(2): $127-135$.

Slameto, (2010), Belajar dan Faktor-Faktor yang Mempengaruhinya, Rineka Cipta, Jakarta.

Trianto, (2009), Mendesain Model Pembelajaran Inovatif-Progresif, Kencana, Jakarta.

Ziqri, I., M., dan Supriyanto, (2014), Efektivitas Model Pembelajaran Creative Problem Solving pada Materi Sistem Pernapasan di SMAN 1 Jatibarang Brebes, Unnes Journal of Biology Education, 3(3): $254-260$. 